\title{
How the Interplay between Consumer Motivations and Values Influences Organic Food Identity and Behavior
}

\author{
Hansen, Torben; Ingerslev Sørensen, Maria; Riwerts Eriksen, Marie-Louise
}

\author{
Document Version \\ Accepted author manuscript \\ Published in: \\ Food Policy \\ DOI: \\ 10.1016/j.foodpol.2017.11.003 \\ Publication date: \\ 2018 \\ License \\ CC BY-NC-ND
}

Citation for published version (APA):

Hansen, T., Ingerslev Sørensen, M., \& Riwerts Eriksen, M-L. (2018). How the Interplay between Consumer Motivations and Values Influences Organic Food Identity and Behavior. Food Policy, 74, 39-52.

https://doi.org/10.1016/j.foodpol.2017.11.003

Link to publication in CBS Research Portal

\section{General rights}

Copyright and moral rights for the publications made accessible in the public portal are retained by the authors and/or other copyright owners and it is a condition of accessing publications that users recognise and abide by the legal requirements associated with these rights.

\section{Take down policy}

If you believe that this document breaches copyright please contact us (research.lib@cbs.dk) providing details, and we will remove access to the work immediately and investigate your claim.

Download date: 26. Apr. 2023
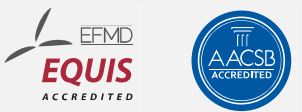


\title{
How the Interplay between Consumer Motivations and Values Influences Organic Food Identity and Behavior
}

\section{Torben Hansen, Maria Ingerslev Sørensen, and Marie-Louise Riwerts Eriksen}

\author{
Journal article (Accepted manuscript*)
}

\section{Please cite this article as:}

Hansen, T., Ingerslev Sarensen, M., \& Riwerts Eriksen, M-L. (2018). How the Interplay between Consumer Motivations and Values Influences Organic Food Identity and Behavior. Food Policy, 74, 39-52.

https://doi.org/10.1016/j.foodpol.2017.11.003

D01: 10.1016/.j.foodpol.2017.11.003

* This version of the article has been accepted for publication and undergone full peer review but has not been through the copyediting, typesetting, pagination and proofreading process, which may lead to differences between this version and the publisher's final version AKA Version of Record.

Uploaded to CBS Research Portal: August २०19

(C) 2019. This manuscript version is made available under the CC-BY-NC-ND 4.0 license http://creativecommons.org/licenses/by-nc-nd/4.0/ 
How the interplay between consumer motivations and values influences organic food identity and behavior

\author{
By \\ Torben Hansen, Professor, Ph.D. \\ Department of Marketing, \\ Copenhagen Business School, \\ Solbjerg Plads 3 , \\ 2000 Frederiksberg, Denmark, \\ Tel. +4538152100, \\ Email: th.marktg@cbs.dk \\ Maria Ingerslev Sørensen, MSc. EMF \\ Jr. Category Development Manager \\ Mondelez International \\ Søndre Ringvej 55 \\ 2605 Brøndby, Denmark \\ Tel. +4526175294 \\ Email: maria.soerensen@mdlz.com
}

Marie-Louise Riewerts Eriksen, MSc. EMF

Audience Director

Concept:CPH

Bredgade 33A

1260 København K

Tel. +4526181468

Email: marie-louise@concept.dk 


\title{
How the interplay between consumer motivations and values influences organic food identity and behavior
}

\begin{abstract}
This study develops a baseline model specifying expected relationships between consumer motivations (health, environmental, and social consciousness), organic food identity, and organic food behavior. Based on an online survey of 1,176 Danish food consumers, we investigate whether these relationships are influenced by different levels of personal values (self-transcendence, openness to change, self-enhancement, and conservation). We find that health consciousness has a higher positive influence on organic food identity with higher levels of all four investigated personal values. When openness to change is low, health consciousness has a positive effect on intentional organic food behavior through organic food identity, whereas social consciousness has a negative effect on intentional organic food behavior through organic food identity. Our results provide guidance to those seeking to segment organic food markets based on consumers' motivations and values.
\end{abstract}

Keywords: Organic food behavior; organic food identity; personal values; consumer organic food motivations. 


\section{Introduction}

Several recent studies and reports have suggested a growing consumer trend towards organic food purchases (D’Amico et al., 2016; Lee, 2016; McFadden and Huffman, 2017). Consumer choices for organic foods are of interest to food policymakers for many reasons, including that (a) the production of organic foods involves the use of environmentally sustainable techniques, which may positively impact ecological systems and bio-diversity (D'Amico et al., 2016; Van Loo et al., 2017; Padel et al., 2009) and (b) that links between organic food behavior and value elements such as fairness and human health are often suggested (e.g., Padel et al., 2009; De Marchi et al., 2016). Consumers may have various reasons for purchasing and consuming organic food, including health, taste, animal welfare, and environmental consequences (Aertsens et al., 2009; Hasselbach and Roosen, 2015), personal values and trust (Grebitus et al., 2015), and identities and motivations (De Pelsmacker et al., 2016; Hasselbach and Roosen, 2015), among others. However, the question of why people buy or do not buy organic food is still not fully understood (Hasselbach and Roosen, 2015; Kareklas et al., 2014).

Even though motivations and personal values are important determinants of proenvironmental and organic food behavior (e.g., De Pelsmacker et al., 2016; Kilbourne and Beckmann, 1998), and the literature has suggested researching the links between articulated value orientations and consumer behavior (Thompson and Troester, 2002; De Maya et al., 2011), the relationships among motivations, values, identity, and consumer organic food behavior remain poorly understood. For example, to what extent do consumers' organic food behavior reflect intuitive and consistent relationships between their own motivations, values, and food identity (De Marchi et al., 2016)?

The aim of this study is twofold. First, we develop and present a baseline model, which specifies expected relationships between consumer motivations (health, environmental, and social consciousness), organic food identity, and organic food behavior. Second, based on a survey sample of 1,176 food consumers we investigate whether these relationships are moderated by different 
levels of personal values. We consider three basic concepts in analyzing consumer choices for organic products. These are personal motivations, personal values, and organic food identity. The results of this study may be highly important for policymakers, food authorities, food managers, and others seeking solutions to environmental problems that require behavioral change.

\section{Conceptual framework}

\subsection{Baseline model part}

Consumer identities are often acknowledged to mediate the link between consumer motivations and behavior (De Pelsmacker et al., 2016), which also can be expressed as a hierarchical motivationalidentity-behavior perspective (Jayawardhena, 2004). This view is also consistent with established consumer behavior paradigms (e.g., Warshaw, 1980; Ajzen and Fishbein, 1973), suggesting that identity can be seen as an intervening variable between consumer psychographics and behavior (Arnocky et al., 2007) and with research suggesting that consumers generally prefer consumption that is congruent with their perceived identity (Belk, 1988). We build upon this perspective in the proposed organic food identity model (Figure 1).

Our model starts from the expectation that organic food identity is a 'primary' direct drive of organic food behavior (Rise et al., 2010). In broad terms, self-identity relates to how individuals perceive their role in the social structure (Stets and Burke, 2003), which in turn may influence how individuals adopt expectations to accompany the role, and tend to act to represent these expectations (De Pelsmacker et al., 2016). Organic food identity is an individual's overall perceived identification with the role of being an organic food consumer.

A literature review suggests that three consumer motivations, in particular, may be related to consumer organic behavior: Environmental, health, and social consciousness, respectively. 


\section{Fig. 1.}

Organic food identity model.

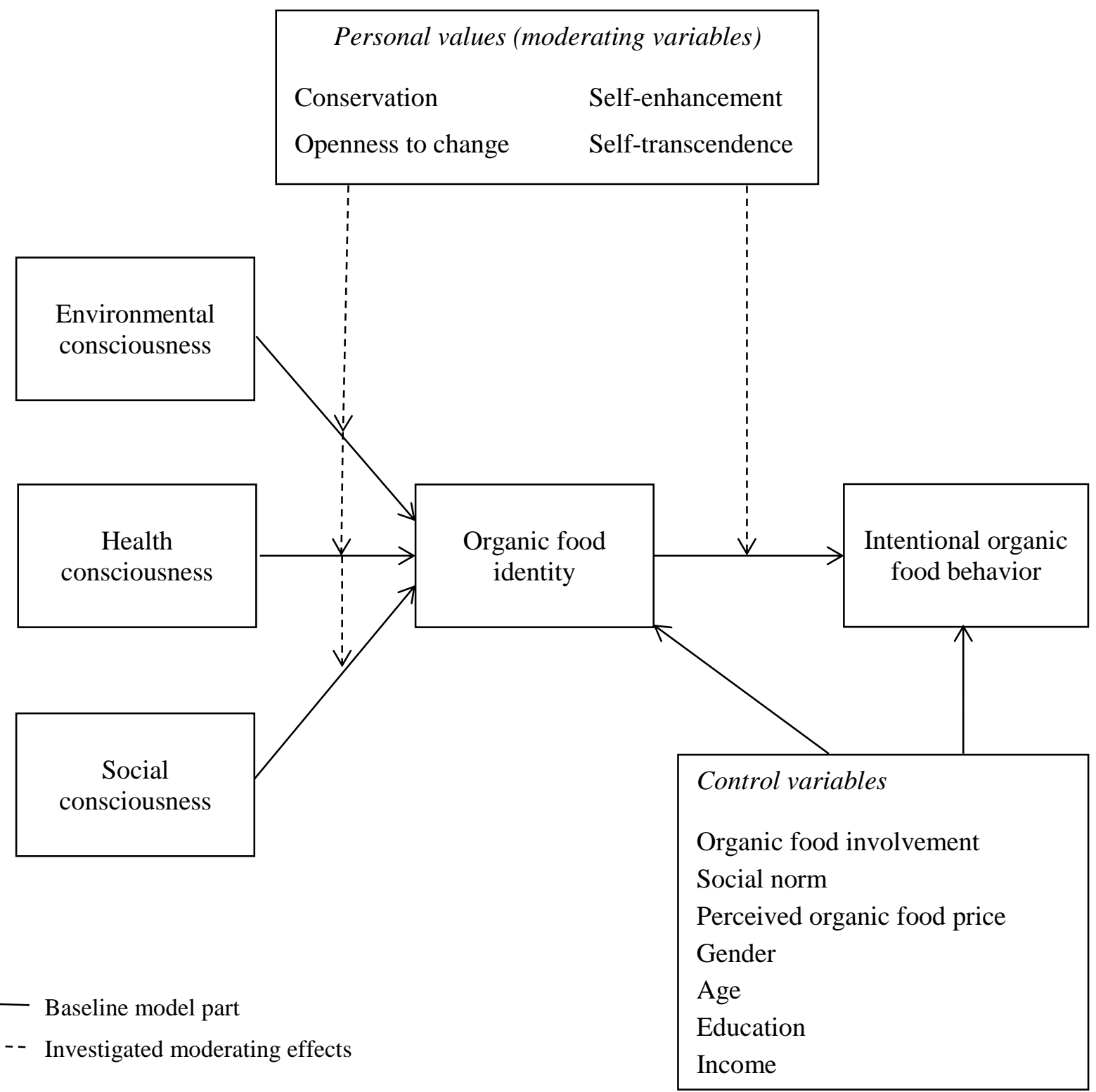

These can be viewed as representing consumer motivations because they are criteria, which may be used by consumers to select and justify their food behavior (Grunert and Juhl, 1995). While some previous studies have suggested direct links between consumer motivations and behavior (Kriwy and Mecking, 2012; Ureña et al., 2008) we suggest in our baseline model that this link is mediated by organic food identity. Our suggestion is consistent with a substantial amount of empirical research, which indicates that the relationships between consumer motives and (organic) 
food behavior are mediated by constructs such as attitude and identity (e.g., Lee, 2016; Michaelidou and Hassan, 2008; Sparks and Shepherd, 1992).

Consumers that adhere to environmental consciousness are motivated by products that are considered environmentally friendly and not harmful to the environment (Michaelidou and Hassan, 2008). Environmental consciousness has been identified as one of the most important drivers of consumer organic food behavior (D’Amico et al., 2016).

Health consciousness refers to consumers' readiness to identify with and to undertake health actions (Becker et al., 1977). Even though there is an ongoing debate concerning whether organic food is more nutritious than conventional food (Hasselbach and Roosen, 2015), several studies point to the high importance of health as a motivator for organic food consumers (e.g., Kriwy and Mecking, 2012; Tarkiainen and Sundqvist, 2009).

While environmental consciousness captures concern for the environment, social consciousness captures concern for society and/or for the consumer's social surroundings (Webster, 1975; Iyer et al., 2016; Atkinson, 2012). For socially conscious consumers, organic marketplace behaviors offer a viable and meaningful way to connect their private concerns (e.g., concern for one's own health) with concerns for their social surroundings (e.g., concerns for the health of one's family) (Atkinson, 2012; Magnusson et al., 2003; De Maya et al., 2011).

Health, environmental, and social consciousness differ in the sense that health consciousness can be regarded as a more egoistic motive (benefits the individual), social consciousness as a mixture of egoistic/altruistic motives (benefits her/his family) while consideration for the environment is more altruistic (benefits the environment rather than the individual) (Magnusson et al., 2003).

In line with previous research considering green and/or organic behavior (e.g., De Pelsmacker et al., 2016; De Maya et al., 2011) we focus on consumers' intentional organic food behavior. This is because consumers' intentional behavior is believed to more clearly transmit values, motivations, and identity than actual (past) behavior since the latter may more likely have 
been affected by market factors such as organic food availability and distance to market (e.g., Rise et al., 2010).

\subsection{Research questions: The effects of personal values}

Consumer values are central to consumer decision-making and can be described as broad psychological constructs that could affect consumers' attitudes, interests, and behavior (Grebitus et al., 2015). Claeys et al. (1995) even claim that "values are the ultimate source of choice criteria that drive buying behavior" (p. 193). Values are trans-situational goals that serve the interest of individuals or groups and act as principles that guide people in their lives and in their behavioral considerations (Schwartz and Sagiv, 1995). This separates values from attitudes, which often are more oriented toward specific choices and/or situations.

Past research has suggested a number of value measurement systems, including Schwartz' theory about values (Schwartz, 1994; Schwartz and Sagiv, 1995), Rokeach's value system (RVS) (Rokeach, 1973; Johnston, 1995), and Kahle's List of Values (LOV) (Kahle and Kennedy, 1989). LOV is more directed to the individual, while RVS has a more social orientation (Marchand and Khallaayoune, 2010). However, LOV does not contain certain values, especially self-transcendence, which previous research has found relevant as motivational goals for consumer 'free-of' behaviors (e.g., Hansen et al., 2012). Also, since RVS is concerned with values far from everyday life, such as world peace and the like, this measurement system was also not considered appropriate for this study. Instead, we found Schwartz' value system to be the most suitable for the present research since it offers a representation of values (including self-transcendence) that are often linked to organic food behavior (Padel et al., 2009).

The Schwartz measurement system contains 10 values and four higher-order value types (Schwartz and Sagiv, 1995). The higher-order values are self-transcendence, openness to change, self-enhancement, and conservation. Self-enhancement emphasizes pursuit of self-interest and encompasses power and achievement values. Self-transcendence relates to individuals' concern for 
the welfare and interests of others. It encompasses universalism and benevolence values and opposes self-enhancement. Openness to change relates to independent actions, thought and feeling, and readiness for new experiences. It encompasses self-direction and stimulation values. Conservation emphasizes order, self-restriction, and resistance to change. It encompasses conformity and tradition values, security, and opposes openness to change. Previous research has in several instances (e.g., Kilbourne et al., 2005; Hansen et al., 2012) used these higher-order value types as measurement variables in the analysis of human value structures, and this approach is also used in the present study.

We expect that the difference in importance that individuals attach to personal values may lead to differences in the relative importance of each of the paths in the conceptual framework displayed in Figure 1. For example, consumers adhering more to self-enhancement values may be more likely to exhibit a positive relationship between egoistic motives, such as health consciousness, and organic food identity. On the other hand, consumers adhering more to selftranscendent values may be more likely to show a positive relationship between altruistic motives, such as environmental consciousness, and organic food identity. Also, consumers adhering more to self-enhancement values may feel more inclined to express their organic food identity directly into future intentions to buy organic food, whereas consumers adhering more to self-transcendence values may be less urged to express their organic identity into corresponding food behavior. Food consumers scoring high on openness to change may be more likely to establish a more 'modern' (organic) food identity (as opposed to a more 'conventional' food identity) on the basis of the three types of motivations included in our framework, whereas consumers with high conservation may exhibit less tendency to develop their food identity even if motivated. People with a high openness to change are more likely to be hedonistic and sensation-seeking (De Pelsmacker et al., 2016). Consequently, they may primarily be driven by egoistic motivations to express their organic food identity in their behavioral intentions, and care less about environmental concerns.

In summary, the research questions we seek to answer in this study are: 
RQ1. In what way does organic food identity mediate the relationships between consumers' organic food motivations and intentional organic food behavior?

RQ2. In what way do personal values moderate the relationships between consumers' organic food motivations, organic food identity, and intentional organic food behavior?

RQ3. To what extent do personal values determine the mediating role of organic food identity in the relationship between consumer organic food motivations and intentional organic food behavior?

\subsection{Control variables}

A number of control variables that may be related to the endogenous constructs (constructs that act as dependent variables in at least one of the model relationships, i.e., organic food identity and intentional organic food behavior) in the baseline model are taken into account (e.g., Greene, 2000). These variables are organic food involvement, social norms, perceived organic food price, income, gender, age, and education.

Organic food involvement is defined as the extent to which individuals are personally interested in a range of issues related to organic food behavior (Hansen and Thomsen, 2017). Consumers who are highly involved with organic food issues are likely to make a significant effort to process organic food information and may be more inclined to maintain organic food identity and behavior (Tarkiainen and Sundqvist, 2009).

Social norms can be conceptualized as jointly-recognized agreements regarding appropriate or inappropriate behavior (Krupka and Weber, 2009). According to social comparison theory, consumers may use their perceptions of peer norms as a standard against which to compare their own beliefs and intentions (e.g., O'Fallon and Butterfield, 2012), which in turn may influence their identity and future decision-making (e.g., Krupka and Weber, 2009). 
Also, past research indicates that females (vs. males) (McFadden and Huffman, 2017), younger people (Grebitus et al., 2015), and people with higher education (Paul and Rana, 2012) are more likely to show organic and sustainable food behavior. Thus, gender, age and education were included as control variables.

The fact that organic food products are typically higher priced (McFadden and Huffman, 2017; Müller and Gaus, 2015) may cause some consumers to hesitate from considering them as part of their food identity and/or from planning to purchase organic products. Hence, price and income were also included as control variables in the study.

\section{Methodology}

\subsection{Data collection and sample statistics}

The data collection was carried out by the market research agency AudienceProject in March/April 2016 using its online Danish consumer panel. A total of 1,176 respondents completed usable questionnaires. Of the respondents, $45.2 \%$ were women; the average age was 57.4 years and ranged between 15 and 86 years (Table 1). We investigated if the profile of our final sample deviated from the Danish population aged 15-86 on gender, education, and income level. $\chi^{2}$-tests of differences between sample and population frequencies on each of these criteria produced $p$-values $<0.05$.

Specifically, men were overrepresented and income and educational level were both above average when compared to the population. Hence, in order to avoid possible bias of our estimates post-stratification survey weights were utilized (Holt and Smith, 1979). Survey weights control for some groups being over- or underrepresented in the sample. The survey weights were calculated by (a) dividing the population proportion in each of the gender, age, income, and educational level categories with the corresponding proportions in the survey sample and then (b) multiplying these separate weights to calculate the total weights (Lance and Hattori, 2016). A comparison of the results with and without the weights revealed no substantial differences; all model relationships that 
were significant/non-significant with the weights remained significant/non-significant without the weights. The results section reports the weighted data results.

\section{Table 1}

Socioeconomic characteristics of the sample compared to the Danish population.

\begin{tabular}{|c|c|c|c|}
\hline \multirow[t]{2}{*}{ Variable } & \multirow[t]{2}{*}{ Specification } & \multicolumn{2}{|l|}{ Percentage of the } \\
\hline & & Sample $(n=1176)$ & Danish population (2016) \\
\hline \multirow{2}{*}{ Gender } & Female & 45.2 & 50.3 \\
\hline & Male & 54.8 & 49.7 \\
\hline \multirow[t]{7}{*}{ Age (years) ${ }^{\mathrm{a}}$} & $15-24$ & 3.3 & 15.4 \\
\hline & $25-34$ & 4.3 & 14.8 \\
\hline & $35-44$ & 7.3 & 15.2 \\
\hline & $45-54$ & 20.9 & 17.0 \\
\hline & $55-64$ & 33.1 & 14.7 \\
\hline & $65-74$ & 27.8 & 13.5 \\
\hline & $>74$ & 3.4 & 9.5 \\
\hline \multirow[t]{5}{*}{ Income $(\mathrm{DKK})^{\mathrm{b}, \mathrm{c}}$} & $<200.000$ & 7.9 & 35.5 \\
\hline & 200.000-399.999 & 23.0 & 41.4 \\
\hline & $400.000-749.999$ & 35.2 & 19.4 \\
\hline & $750.000-999.000$ & 12.9 & 1.9 \\
\hline & $>1.000 .000$ & 7.4 & 1.6 \\
\hline \multirow[t]{6}{*}{ Education $^{\mathrm{c}}$} & Without any graduation & 0.0 & 0.7 \\
\hline & Primary school & 6.5 & 28.2 \\
\hline & High school & 8.2 & 9.5 \\
\hline & Business training & 23.9 & 32.7 \\
\hline & Short advanced study & 36.7 & 18.3 \\
\hline & $\begin{array}{l}\text { Medium/long } \\
\text { advanced study }\end{array}$ & 20.5 & 10.5 \\
\hline
\end{tabular}

Notes

${ }^{a}$ A small proportion (1.4 percent) of the sample consisted of teenage respondents (aged 15-19). A comparison of the results with and without these respondents revealed no substantial differences.

b 100 DKK (Danish Kroner) $\approx 16$ USD.

${ }^{\mathrm{c}}$ Population percentages are from 2015. 'Business training' includes educations such as carpenter, glazier, and electrician; 'short advanced study' includes undergraduate degrees such as teacher, accountant, and registered nurse; 'medium/long advanced study' includes graduate degrees, i.e., bachelor's, master's, and Ph.D. degrees.

Source (population percentages): Danish Statistical Bureau, DST (2017). 


\subsection{Measurements}

All baseline model and moderating constructs in Figure 1 are treated as latent unobservable variables. The final items for each construct, along with the percentage of respondents in the sample who selected the different items, are summarized in Appendix A.

Five items adapted from the scale proposed by Magnusson et al. (2003) measured environmental consciousness. Health consciousness was measured by five items derived from Squires et al. (2001), whereas social consciousness was measured by five items adapted from Magnusson et al. (2003). The measurement of organic food identity was based on three items derived from Sparks and Shepherd (1992). Intentional organic food behavior was measured by three items derived from Michaelidou and Hassan (2008). The semi-annual European Social Survey's 21-item value instrument was used for measuring the four Schwartz values (conservation, openness to change, self-enhancement, and self-transcendence) (Davidov et al., 2008).

Three items adapted from Steptoe et al. (1995) measured perceived organic food price, whereas organic food involvement was measured by four items derived from Mittal's (1989) involvement scale. Social norm was measured by three items derived from Hansen (2008). Age, gender (with codings: $0=$ female; $1=$ male), income, and educational level were all observed variables.

\subsection{Estimation of the organic food identity model}

The relationships suggested in the organic food identity model were translated into a structural equation model (SEM) consisting of a measurement part (confirmatory factor analysis) (CFA) and a structural equation part (simultaneous linear regression). SEM is particularly suited for estimating the organic food identity model since this method can handle a large number of relationships between latent variables while at the same time taking into account measurement error and control variables. However, a number of pitfalls still exist within SEM methods (see, for example, 
MacCallum and Austin (2000) and Kline (2016)), so we do not provide evidence of definitive causal relationships.

\section{Results}

We begin with a validation of the applied measurement items (CFA) and also examine whether common method bias may pose a serious threat to the analysis and interpretation of the data. We then estimate the proposed organic food identity model (Figure 1). We used SPSS Amos 24 and the weighted correlation matrix to calculate the results using a maximum likelihood estimation procedure.

\subsection{Measurement model results}

CFA was conducted on the nine latent model factors (i.e., including the moderating variables) and the three latent control variables, with each indicator specified to load on its hypothesized latent factor. Table 2 summarizes the CFA results. The measurement model yields a chi-square of 3351.23 (d.f.=753 $p<0.01)$. However, the Hoelter(0.05) (Hoelter, 1983) estimate $(\mathrm{n}=264)$ suggests that the lack of absolute fit can be explained by sample size. Thus, since the chi-square test is highly sensitive to sample size other fit measures are given greater prominence in evaluating model fit (e.g., Ye et al., 2007). The root mean square error of approximation (RMSEA=0.057), the comparative fit index $(\mathrm{CFI}=0.92)$ and the normed fit index $(\mathrm{NFI}=0.90)$ suggest that the measurement model fits the data reasonably well (Bagozzi and Yi, 1988).

Composite reliabilities were all greater than 0.70 with the exception of two instances, which were above 0.60 , indicating a reasonable reliability of measured constructs (Bagozzi and Yi, 1988). Finally, extracted variance was greater than 0.50 for the majority of the latent constructs, which satisfies the threshold value recommended by Fornell and Larcker (1981). 


\section{Table 2}

Confirmatory factor analysis results.

\begin{tabular}{|c|c|c|c|c|}
\hline Construct/indicator & $\begin{array}{l}\text { Standardized } \\
\text { factor loading }\end{array}$ & $\begin{array}{l}\text { Critical } \\
\text { ratio }\end{array}$ & $\begin{array}{l}\text { Composite } \\
\text { reliability }\end{array}$ & $\begin{array}{l}\text { Extracted } \\
\text { variance }\end{array}$ \\
\hline Environmental consciousness & & & 0.95 & 0.80 \\
\hline $\mathrm{X} 1$ & 0.86 & - & & \\
\hline $\mathrm{X} 2$ & 0.90 & 41.48 & & \\
\hline $\mathrm{X} 3$ & 0.87 & 38.11 & & \\
\hline $\mathrm{X} 4$ & 0.93 & 43.41 & & \\
\hline $\mathrm{X} 5$ & 0.90 & 40.60 & & \\
\hline Health consciousness & & & 0.71 & 0.45 \\
\hline X6 & 0.67 & - & & \\
\hline $\mathrm{X} 7$ & 0.61 & 16.00 & & \\
\hline $\mathrm{X} 8$ & 0.73 & 18.37 & & \\
\hline Social consciousness & & & 0.93 & 0.74 \\
\hline X9 & 0.87 & - & & \\
\hline $\mathrm{X} 10$ & 0.92 & 41.86 & & \\
\hline $\mathrm{X} 11$ & 0.81 & 31.60 & & \\
\hline $\mathrm{X} 12$ & 0.88 & 38.08 & & \\
\hline $\mathrm{X} 13$ & 0.82 & 34.19 & & \\
\hline Organic food identity & & & 0.76 & 0.52 \\
\hline $\mathrm{X} 14$ & 0.50 & - & & \\
\hline $\mathrm{X} 15$ & 0.83 & 16.11 & & \\
\hline X16 & 0.79 & 15.88 & & \\
\hline Intentional organic food behavior & & & 0.97 & 0.91 \\
\hline $\mathrm{X} 17$ & 0.95 & - & & \\
\hline $\mathrm{X} 18$ & 0.97 & 75.54 & & \\
\hline X19 & 0.94 & 64.86 & & \\
\hline Conservation & & & 0.69 & 0.36 \\
\hline $\mathrm{X} 20$ & 0.58 & - & & \\
\hline $\mathrm{X} 21$ & 0.65 & 13.32 & & \\
\hline $\mathrm{X} 22$ & 0.56 & 12.31 & & \\
\hline $\mathrm{X} 23$ & 0.60 & 12.84 & & \\
\hline Openness to change & & & 0.76 & 0.44 \\
\hline $\mathrm{X} 24$ & 0.67 & - & & \\
\hline $\mathrm{X} 25$ & 0.64 & 16.17 & & \\
\hline $\mathrm{X} 26$ & 0.72 & 17.33 & & \\
\hline $\mathrm{X} 27$ & 0.62 & 15.86 & & \\
\hline Self-enhancement & & & 0.82 & 0.53 \\
\hline $\mathrm{X} 28$ & 0.74 & - & & \\
\hline $\mathrm{X} 29$ & 0.85 & 23.60 & & \\
\hline $\mathrm{X} 30$ & 0.55 & 16.45 & & \\
\hline X31 & 0.70 & 20.81 & & \\
\hline Self-transcendence & & & 0.64 & 0.48 \\
\hline X32 & 0.80 & - & & \\
\hline $\mathrm{X} 33$ & 0.56 & 10.98 & & \\
\hline Organic food involvement & & & 0.90 & 0.74 \\
\hline $\mathrm{X} 34$ & 0.71 & - & & \\
\hline $\mathrm{X} 35$ & 0.94 & 30.39 & & \\
\hline X36 & 0.92 & 29.61 & & Table 2 contint \\
\hline
\end{tabular}


Social norm

X37

X38

X39

Perceived organic food price

X40

$\mathrm{X} 41$

$\mathrm{X} 42$
0.86

0.70

0.75

0.66

0.55

0.96
0.82

23.32

26.09

Notes

a One item for each construct was set to $1 . \chi^{2}=3351.23$ (d.f. $=753, p<0.01$ ); RMSEA=0.057, CFI=0.92, NFI=0.90, Hoelter(0.05)=264. Sample $n=1,176$. Some items were deleted due to low $(<0.50)$ item-total correlation. The deleted items are marked in Appendix A.

Discriminant validity was assessed using the method proposed by Fornell and Larcker (1981). According to this method, the extracted variance for each individual construct should be greater than the squared correlation (i.e., shared variance) between constructs. When disregarding the control variables (i.e., these were included in the study because of their anticipated high correlations with model constructs) an examination of Table 3 shows that the extracted variance for each of the constructs exceeds the squared correlation except for 'health conscioussness' with respect to its correlation with 'organic food identity' (variance, health consciousness $=0.45<$ squared correlation health consciousness-organic food identity=0.67), although the latter is below the suggested threshold of 0.85 (Frambach et al., 2003). Also, as a path from health consciousness to organic food identity is expected in the conceptual model, the relatively high correlation should not be regarded as a serious violation of discriminant validity.

In order to assess the effects of common-method variance, we re-estimated the measurement model by adding a same-source factor (all main construct items loading on it) to the CFA model (Netemeyer et al., 1997). Common method variance is a known limitation in surveys using selfreported measures and refers to the amount of spurious covariance shared among variables because of the common method used in collecting data (Buckley et al., 1990). Comparing an unconstrained model, in which all indicators are related to a common factor, to one in which these paths are constrained to zero represents a significance test of the effects of the same-source factor. 


\section{Table 3}

Correlations and descriptive statistics.

\begin{tabular}{|c|c|c|c|c|c|c|c|c|c|c|c|c|}
\hline & 1 & 2 & 3 & 4 & 5 & 6 & 7 & 8 & 9 & 10 & 11 & 12 \\
\hline 1. Environmental consciousness & 0.80 & & & & & & & & & & & \\
\hline 2. Health consciousness & $0.24^{\mathrm{a}}$ & 0.45 & & & & & & & & & & \\
\hline 3. Social consciousness & $0.77^{\mathrm{a}}$ & $0.34^{\mathrm{a}}$ & 0.74 & & & & & & & & & \\
\hline 4. Organic food identity & $0.41^{\mathrm{a}}$ & $0.67^{\mathrm{a}}$ & $0.52^{\mathrm{a}}$ & 0.52 & & & & & & & & \\
\hline 5. Intentional organic food behavior & $\mathrm{r} 0.62^{\mathrm{a}}$ & $0.33^{\mathrm{a}}$ & $0.73^{\mathrm{a}}$ & $0.50^{\mathrm{a}}$ & 0.91 & & & & & & & \\
\hline 6. Conservation & $<0.01$ & $0.02^{\mathrm{a}}$ & $<0.01^{\mathrm{b}}$ & 0.02 & $<0.01$ & 0.36 & & & & & & \\
\hline 7. Openness to change & $0.01^{\mathrm{a}}$ & $0.07^{\mathrm{a}}$ & $0.02^{\mathrm{a}}$ & $0.04^{\mathrm{a}}$ & $0.04^{\mathrm{a}}$ & 0.02 & 0.44 & & & & & \\
\hline 8. Self-enhancement & $<0.01$ & $0.01^{\mathrm{b}}$ & $0.01^{\mathrm{a}}$ & $0.03^{\mathrm{a}}$ & $0.03^{\mathrm{a}}$ & $0.16^{\mathrm{a}}$ & $0.22^{\mathrm{a}}$ & 0.53 & & & & \\
\hline 9. Self-transcendence & $0.24^{\mathrm{a}}$ & $0.36^{\mathrm{a}}$ & $0.23^{\mathrm{a}}$ & $0.37^{\mathrm{a}}$ & $0.17^{\mathrm{a}}$ & $0.05^{\mathrm{a}}$ & $0.13^{\mathrm{a}}$ & $0.03^{\mathrm{a}}$ & 0.48 & & & \\
\hline 10. Organic food involvement & $0.68^{\mathrm{a}}$ & $0.36^{\mathrm{a}}$ & $0.73^{\mathrm{a}}$ & $0.51^{\mathrm{a}}$ & $0.78^{\mathrm{a}}$ & $<0.01$ & $0.02^{\mathrm{a}}$ & 0.01 & $0.25^{\mathrm{a}}$ & 0.74 & & \\
\hline 11. Social norm & $0.64^{\mathrm{a}}$ & $0.33^{\mathrm{a}}$ & $0.64^{\mathrm{a}}$ & $0.50^{\mathrm{a}}$ & $0.66^{\mathrm{a}}$ & $<0.01$ & $0.03^{\mathrm{a}}$ & $<0.01$ & $0.17^{\mathrm{a}}$ & $0.72^{\mathrm{a}}$ & 0.60 & \\
\hline 12. Perceived organic food price & $0.63^{\mathrm{a}}$ & $0.32^{\mathrm{a}}$ & $0.62^{\mathrm{a}}$ & $0.51^{\mathrm{a}}$ & $0.79^{\mathrm{a}}$ & $<0.01$ & $0.02^{\mathrm{a}}$ & $0.01^{\mathrm{b}}$ & $0.17^{\mathrm{a}}$ & $0.71^{\mathrm{a}}$ & $0.56^{\mathrm{a}}$ & 0.55 \\
\hline Mean & 3.83 & 5.14 & 4.21 & 4.15 & 4.38 & 4.43 & 4.61 & 3.83 & 5.55 & 4.28 & 4.43 & 4.28 \\
\hline Std. deviation & 1.28 & 1.08 & 1.67 & 1.38 & 1.95 & 1.25 & 1.17 & 1.28 & 1.05 & 1.55 & 1.43 & 1.47 \\
\hline
\end{tabular}

Notes

${ }^{\mathrm{a}} p<0.01 ;{ }^{\mathrm{b}} p \underline{0} .05$.

Averaged scale means are reported; all items were measured on 7-point Likert scales (1=strongly disagree; $7=$ strongly agree).

Coefficients on the diagonal represent the amount of extracted variance for each construct (see also Table 2),

coefficients below the diagonal are squared correlations (i.e., shared variance) between constructs. Sample $n=1,176$ 
The fit of the constrained model was $\chi^{2}=2929.61$ (d.f. $\left.=754\right), \mathrm{CFI}=0.93$; RMSEA $=0.055$. For the unconstrained model, the fit was $\chi^{2}=2879.65$ (d.f. $=713$ ), $C F I=0.94 ;$ RMSEA $=0.053$. The fit of the unconstrained model did not differ from that of the constrained model $\left(\Delta \chi^{2}=49.96, \Delta\right.$ d.f. $=41$, $p=0.16$ ) suggesting that the results are robust with respect to common method variance.

\subsection{Segmentation analysis}

A segmentation (cluster) analysis generated four segments (see Appendix B for details) with segments 1 and 4 representing respondents with mostly low (segment 1) vs. high (segment 4) levels, respectively, of motivational variables, organic food identity, intentional organic food behavior, personal values, organic food involvement, and social norms. In addition, segment 4 comprises more females, with higher educational level and lower perceived price level, than segment 1 respondents. Segments 2 and 3 tend to represent respondents with medium levels of the investigated variables. These results are consistent with the general proposal and findings that associations may exist between baseline model constructs, personal values, and control variables, as outlined in the organic food identity model (Figure 1).

\subsection{Results pertaining to RQ1}

The baseline model fits the data reasonably well $\left(\chi^{2}=2527.44\right.$, d.f. $=405, p<0.01 ; \mathrm{CFI}=0.93$; $\mathrm{NFI}=0.92 ; \mathrm{RMSEA}=0.070 ;$ Hoelter(0.05)=204). Of the control variables, organic food involvement $(\beta=0.54, p<0.01)$ was positively and gender $(\beta=-0.06, p=0.01)$ was negatively related to organic food identity. Organic food involvement $(\beta=0.53, p<0.01)$ and social norm $(\beta=0.16, p<0.01)$ were both positively related to intentional organic food behavior, whereas perceived organic food price $(\beta=-0.29, p<0.01)$ and age $(\beta=-0.03, p=0.03)$ were both negatively related to intentional organic 
food behavior. We then explored whether organic food identity mediates the relationships between consumer organic food motivations and intentional organic food behavior (i.e., RQ1) (Table 3).

The results suggest that health consciousness had a positive influence on organic food identity $(\beta=0.58, p<0.01)$, whereas social consciousness had a negative influence on organic food identity $(\beta=-0.28, p<0.01)$. The two other paths specified in the baseline model were non-significant meaning that organic food identity did not act as a mediating variable in the relationship between personal motivations and organic food behavior.

\subsection{Results pertaining to $R Q 2$ and $R Q 3$}

The moderating effects pertaining to the four personal values were investigated using multiplegroup latent variable structural equation modeling (SEM) analysis with chi-square difference tests (Table 4). 
Table 4

Estimated standardized coefficients.

\begin{tabular}{|c|c|c|c|c|c|c|c|c|c|c|}
\hline \multirow[b]{4}{*}{ Relationship } & & & \multicolumn{8}{|c|}{ Moderating effects } \\
\hline & \multirow{2}{*}{\multicolumn{2}{|c|}{ Main model effects }} & \multicolumn{2}{|c|}{ Conservation } & \multicolumn{2}{|c|}{ Openness to change } & \multicolumn{2}{|c|}{ Self-enhancement } & \multicolumn{2}{|c|}{ Self-transcendence } \\
\hline & & & \multirow{2}{*}{$\begin{array}{c}\text { Low } \\
\beta(\mathrm{SE}) t \text {-Value }\end{array}$} & \multirow{2}{*}{$\begin{array}{c}\text { High } \\
\beta(\mathrm{SE}) t \text {-Value }\end{array}$} & \multirow{2}{*}{$\begin{array}{c}\text { Low } \\
\beta(\mathrm{SE}) t \text {-Value }\end{array}$} & \multirow{2}{*}{$\begin{array}{l}\text { High } \\
\beta(\mathrm{SE}) t \text {-Value }\end{array}$} & \multirow{2}{*}{$\begin{array}{l}\text { Low } \\
\beta(\mathrm{SE}) t \text {-Value }\end{array}$} & \multirow{2}{*}{$\begin{array}{l}\text { High } \\
\beta(\mathrm{SE}) t \text {-Value }\end{array}$} & \multirow{2}{*}{\multicolumn{2}{|c|}{ 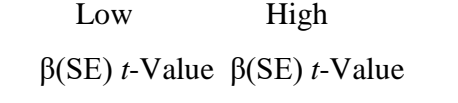 }} \\
\hline & $\beta(\mathrm{SE}) t$ & $t$-Value & & & & & & & & \\
\hline \multicolumn{11}{|l|}{ Main model relationships } \\
\hline \multicolumn{11}{|l|}{ Environmental consciousness } \\
\hline$\rightarrow$ organic food identity & $0.08(0.04)$ & 1.27 & $0.05(0.07) 0.60$ & $0.08(0.08) 0.60$ & $0.02(0.08) 0.22$ & $0.03(0.06) 0.39$ & $0.03(0.06) 0.37$ & $0.08(0.07) 0.67$ & $0.02(0.07) 0.25$ & $0.21(0.10) 1.53$ \\
\hline \multicolumn{11}{|l|}{ Health consciousness } \\
\hline$\rightarrow$ organic food identity & $0.58(0.07)$ & $10.11^{\mathrm{a}}$ & $0.51(0.12) 6.98^{a}$ & $0.66(0.09) 6.75^{a}$ & $0.50(0.11) 6.07^{a}$ & $0.61(0.10) 6.84^{a}$ & $0.56(0.12) 6.77^{a}$ & $0.63(0.08) 7.86^{a}$ & $0.45(0.09) 6.22^{a}$ & $0.72(0.15) 6.27^{a}$ \\
\hline \multicolumn{11}{|l|}{ Social consciousness } \\
\hline$\rightarrow$ organic food identity & $-0.28(0.07)$ & $-2.61^{a}$ & $-0.34(0.10)-2.58^{b}$ & $-0.20(0.13)-0.82$ & $-0.44(0.12)-2.59$ & $0.01(0.09) 0.07$ & $-0.08(0.09)-0.62$ & $-0.43(0.11)-2.25^{b}$ & $-0.27(0.13)-1.40$ & $-0.36(0.11)-2.23^{b}$ \\
\hline \multicolumn{11}{|l|}{ Organic food identity } \\
\hline$\rightarrow$ intentional organic food behavior & $0.01(0.04)$ & 0.47 & $0.08(0.06) 1.95$ & $-0.04(0.07)-1.20$ & $0.10(0.08) 2.12^{b}$ & $-0.02(0.06)-0.48$ & $0.03(0.06) 0.74$ & $0.01(0.07) 0.20$ & $0.12(0.05) 2.84^{\mathrm{a}}$ & $-0.01(0.06)-0.23$ \\
\hline \multicolumn{11}{|l|}{ Controls } \\
\hline \multicolumn{11}{|l|}{ Organic food involvement } \\
\hline \multicolumn{11}{|l|}{ Social norm } \\
\hline$\rightarrow$ organic food identity & $-0.01(0.06)$ & 6) -0.07 & $0.15(0.11) 1.03$ & $-0.29(0.09)-1.81$ & $0.18(0.13) 1.06$ & $-0.14(0.08)-1.03$ & $0.11(0.10) 0.76$ & $-0.15(0.09)-1.03$ & $0.07(0.08) 0.60-$ & $-0.19(0.14)-1.00$ \\
\hline \multicolumn{11}{|l|}{ Perceived organic food price } \\
\hline$\rightarrow$ organic food identity & $-0.11(0.08)$ & ) -1.03 & $-0.14(0.18)-0.85$ & $-0.12(0.14)-0.58$ & $-0.14(0.21)-0.71$ & $-0.18(0.09)-1.38$ & $-0.13(0.12)-1.05$ & $-0.06(0.13)-0.33$ & $-0.01(0.10)-0.02$ & $2-0.51(0.26)-1.80$ \\
\hline \multicolumn{11}{|l|}{ Gender } \\
\hline \multicolumn{10}{|l|}{ Age } & $6-0.08(0.09)-1.85$ \\
\hline $\begin{array}{l}\rightarrow \text { organic food identity } \\
\text { Education }\end{array}$ & $-0.04(0.06)$ & -1.64 & $-0.05(0.01)-1.41$ & $-0.03(0.01)-0.64$ & $-0.09(0.03)-2.48^{b}$ & $-0.03(0.01)-0.58$ & $-0.04(0.01)-1.12$ & $2-0.15(.01)-0.39$ & $0.02(0.03) 0.48$ & $-0.14(0.03)-2.88^{a}$ \\
\hline $\begin{array}{l}\rightarrow \text { organic food identity } \\
\text { Income }\end{array}$ & $0.31(0.02)$ & 1.20 & $0.01(0.04) 0.10$ & $0.08(0.03) 2.01^{b}$ & $0.06(0.04) 1.52$ & $-0.01(0.03)-0.30$ & $0.08(0.04) 2.04^{b}$ & b $-0.02(0.03)-0.46$ & $0.01(0.04) 0.17$ & $7 \quad 0.03(0.04) 0.73$ \\
\hline$\rightarrow$ organic food identity & $-0.05(0.02)$ & ) -1.94 & $-0.06(0.04)-1.62$ & $-0.05(-0.03)-1.63$ & $-0.03(0.04)-0.74$ & $-0.06(0.03)-1.63$ & $-0.07(0.04)-1.79-$ & $-0.02(0.03)-0.65$ & $-0.01(0.04)-0.14$ & $-0.11(0.04)-2.34^{b}$ \\
\hline \multicolumn{11}{|l|}{ Organic food involvement } \\
\hline $\begin{array}{l}\rightarrow \text { intentional organic food behavior } \\
\text { Social norm }\end{array}$ & $0.53(0.13)$ & $7.00^{\mathrm{a}}$ & $0.12(0.27) 0.77$ & $0.67(0.21) 6.00^{\mathrm{a}}$ & $0.91(0.34) 4.80^{\mathrm{a}}$ & $0.43(0.15) 5.12^{\mathrm{a}}$ & $0.58(0.19) 5.34^{\mathrm{a}} 0$ & $0.45(0.20) 4.04^{a}$ & $0.54(0.16) 6.17^{a}$ & $0.37(0.25) 2.76^{a}$ \\
\hline$\rightarrow$ intentional organic food behavior & $0.16(0.05)$ & $3.62^{\mathrm{a}}$ & $0.39(0.10) 4.67^{a}$ & $-0.01(0.08)-0.23$ & $0.01(0.11) 0.02$ & $0.19(0.08) 2.98^{a}$ & $0.14(0.08) 2.15^{b}$ & $0.20(0.08) 2.93^{a}$ & $0.15(0.07) 2.70^{\mathrm{a}}$ & $0.17(0.09) 2.35^{\mathrm{b}}$ \\
\hline
\end{tabular}


$\rightarrow$ intentional organic food behavior

$\rightarrow$ intentional organic food behavior Education

$\rightarrow$ intentional organic food behavior $-0.03(0.01)-2.17^{\mathrm{b}}$

$-0.04(0.01)-2.52^{b}-0.01(0.03)-0.34 \quad-0.01(0.01)-0.28 \quad-0.04(0.07)-2.36^{b}$

$-0.04(0.01)-2.27^{\mathrm{b}} \quad-0.03(0.01)-1.25 \quad 0.01(0.01) 0.76 \quad-0.07(0.01)-4.01^{\mathrm{a}}$

$0.02(0.02) \quad 1.23$ $-0.02(0.03)-1.01 \quad 0.04(0.03) 1.95$

$0.02(0.04) 0.78$

0.03(0.03) 1.85

$0.01(0.03) 0.75 \quad 0.01(0.03) 0.62$

$0.01(0.03) 0.73 \quad 0.01(0.03) 0.39$

$\rightarrow$ intentional organic food behavior

Notes Model fit (baseline model effects): $\chi^{2}=2527.44$, d.f. $=405, p<0.01 ; \mathrm{CFI}=0.93 ; \mathrm{NFI}=0.92 ; \mathrm{RMSEA}=0.070 ;$ Hoelter(0.05)=204.

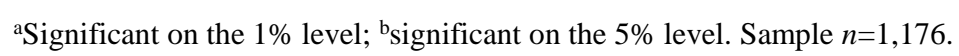

$\mathrm{R}^{2}$ (organic food identity) $=0.83 ; \mathrm{R}^{2}$ (intentional organic food behavior) $=0.93$.

Coefficients in bold are statistically different ( $p \leq 0.05)$; only differences in which at least one coefficient was significant were inspected.

Median splits created the low vs. high levels of the four personal values (i.e., conservation, openness to change, self-enhancement, and self-transcendence, respectively). 
Conservation: The positive influence of health consciousness on organic food identity was significantly higher for consumers with a high level of conservation $(\beta=0.66, p<0.01)$ than for consumers with a low level of conservation $(\beta=0.51, p<0.01)$ A chi-square difference test suggested that the difference between coefficients was significant $\left(\Delta \chi^{2}=31.74, \Delta\right.$ d.f. $\left.=2, p<0.01\right)$. Also, social consciousness had a negative effect on organic food identity when the level of conservation is low ( $\beta=-0.34, p=0.01)$, whereas no significant effect was found when the level of conservation is high $(\beta=-0.20, p=0.41)\left(\Delta \chi^{2}=7.69, \Delta\right.$ d.f. $\left.=2, p=0.02\right)$. No moderated mediating effects could be investigated for conservation since organic food identity did not influence organic food behavior for any of the two levels of conservation.

Openness to change: Health consciousness had a higher positive influence on organic food identity when the level of openness to change is high $(\beta=0.61, p<0.01)$ vs. low $(\beta=0.50, p<0.01)$ $\left(\Delta \chi^{2}=24.09, \Delta\right.$ d.f. $\left.=2, p<0.01\right)$.

Also, social consciousness had a negative influence on organic food identity $(\beta=-0.44$, $p<0.01)$ when openness to change is low, whereas no significant effect was detected when openness to change is high $(\beta=0.01, p=0.95)\left(\Delta \chi^{2}=8.14, \Delta\right.$ d.f. $\left.=2, p=0.02\right)$. Furthermore, organic food identity had a positive influence on intentional organic food behavior when openness to change is low $(\beta=0.10, p=0.03)$ but showed no significant influence when openness to change is high $(\beta=-0.02$, $p=0.63)\left(\Delta \chi^{2}=7.84, \Delta\right.$ d.f. $\left.=2, p=0.02\right)$.

To test the two potential moderated mediating (indirect) effects (i.e., health consciousness on organic food behavior through organic food identity and social consciousness on organic food behavior through organic food identity, respectively), we used bias-corrected bootstrapping to generate a 95\% confidence interval around each of the indirect effects, where mediation occurs if the confidence interval excludes zero. When openness to change is on a low level, the results indicated that health consciousness had a significant indirect effect on organic food behavior through organic food identity $(95 \%$ confidence interval $[\mathrm{CI}]=[0.02,0.24])$, whereas the indirect 
effect was non-significant when openness to change is on a high level (95\% confidence interval $[C I]=[-0.18,0.08])$. Hence, our results suggest that the mediating effect of health consciousness on organic food behavior through organic food identity is moderated by openness to change.

Also suggesting moderated mediation, we found that the indirect effect of social consciousness on intentional organic food behavior, through organic food identity, was negative and significant when openness to change was on a low level $(95 \%$ confidence interval $[\mathrm{Cl}]=[-0.35$, 0.03]), whereas the indirect effect was non-significant when openness to change was on a high level $(95 \%$ confidence interval $[\mathrm{Cl}]=[-0.11,0.04])$.

Self-enhancement: Health consciousness had a higher influence on organic food identity when self-enhancement is on a high level $(\beta=0.63, p<0.01)$ than when self-enhancement is on a low level $(\beta=0.56, p<0.01)\left(\Delta \chi^{2}=39.34, \Delta\right.$ d.f. $\left.=2, p<0.01\right)$. Also, social consciousness had a higher negative influence on organic food identity when self-enhancement is on a high level $(\beta=-0.43$, $p=0.03)$ vs. a low level $(\beta=-0.08, p=0.54)\left(\Delta \chi^{2}=6.02, \Delta\right.$ d.f. $\left.=2, p=0.05\right)$.

Self-transcendence: When the level of self-transcendence is high, health consciousness had a higher positive influence on organic food identity $(\beta=0.72, p<0.01)$ as compared with when selftranscendence is on a low level $(\beta=0.45, p<0.01)\left(\Delta \chi^{2}=45.02, \Delta\right.$ d.f. $\left.=2, p<0.01\right)$. Also, organic food identity has a positive influence on intentional organic food behavior when self-transcendence is on a low level $(\beta=0.12, p<0.01)$, whereas no significant influence was detected when selftranscendence was on a high level $(\beta=-0.01, p=0.63)\left(\Delta \chi^{2}=5.80, \Delta\right.$ d.f. $\left.=2, p=0.05\right)$. When selftranscendence is on a low level, the results indicated that the indirect effect of health consciousness on organic food behavior, through organic food identity, was significant (95\% confidence interval $[\mathrm{Cl}]=[0.01,0.28])$, whereas the indirect effect was non-significant when self-transcendence is on a high level $(95 \%$ confidence interval $[\mathrm{Cl}]=[-0.28,0.07])$. Hence, our results suggest that the mediating effect of health consciousness on intentional organic food behavior through organic food identity is moderated by self-transcendence. 
Control variables: Organic food involvement had a higher positive effect on organic food identity with higher levels of conservation and self-enhancement, respectively, and with lower levels of self-transcendence. In addition, males were more negatively related to organic food identity with higher levels of openness to change, whereas age was more negatively related to organic food identity with lower levels of openness to change and higher levels of selftranscendence. Education was more positively related to organic food identity with higher levels of conservation and lower levels of self-enhancement. Income was more negatively related to organic food identity with higher levels of self-transcendence.

Organic food involvement was more positively related to intentional organic food behavior with higher levels of conservation and lower levels of openness to change, self-enhancement, and self-transcendence. Furthermore, social norm had a higher positive effect on intentional organic food behavior with lower levels of conservation and with higher levels of openness to change and self-enhancement. Also, perceived organic food price was more negatively related to intentional organic food behavior with higher levels of openness to change, self-enhancement, and selftranscendence, respectively, and with lower levels of conservation. Finally, age was more negatively related to intentional organic food behavior with lower levels of conservation and selfenhancement and with higher levels of openness to change and self-transcendence.

\subsection{Competing models}

To explore the robustness of the proposed organic food identity model four competing models were specified. In competing model 1, the three consumer motivations (i.e., environmental consciousness, health consciousness, and social consciousness, respectively) were allowed also to have a direct effect on intentional organic food behavior. The competing model was a reasonable fit to the data $\left(\chi^{2}=2504.94\right.$, d.f. $=342, p<0.01 ; \mathrm{CFI}=0.93 ; \mathrm{NFI}=0.92 ; \mathrm{RMSEA}=0.070$; Hoelter(0.05) $=184)$. However, the Hoelter (0.05) estimate, $n=184$, suggested that the lack of 
absolute fit in this model could not be explained by sample size. In the competing model, social consciousness was negatively related to intentional organic food behavior $(\beta=-0.31, p<0.01)$. This result is consistent with the finding obtained in the baseline model that social consciousness had a negative influence on organic food identity $(\beta=-0.28, p=0.01)$.

Competing model 2 allowed the four personal values (self-transcendence, openness to change, self-enhancement, and conservation) also to have a direct influence on intentional organic food behavior. While competing model 2 showed an improvement in the Hoelter(0.05) estimate $\left(\chi^{2}=1276.37\right.$, d.f. $=342, p<0.01 ; \mathrm{CFI}=0.91 ; \mathrm{NFI}=0.89 ; \mathrm{RMSEA}=0.056 ;$ Hoelter$\left.(0.05)=269\right)$, none of the personal values significantly influenced intentional organic food behavior ( $p$-values ranged from 0.10 to 0.83$)$.

The organic food identity model specifies organic food involvement as a control variable that relates to the endogenous constructs 'organic food identity' and 'intentional organic food behavior', respectively. While these relationships are consistent with past research suggesting that involvement in a specific area may lead a person to establish an identity related to that area (Tarkiainen and Sundqvist, 2009), other results suggest that identity may positively influence involvement (e.g., Fischer and Arnold, 1994). Hence, in competing model 3, organic food involvement replaced organic food identity as an endogenous construct in the model, whereas organic food identity was included as a control variable affecting both organic food involvement and intentional organic food behavior. While the overall model fit statistics was similar to that of the baseline model $\left(\chi^{2}=2527.44\right.$, d.f. $=405, p<0.01 ; \mathrm{CFI}=0.93 ; \mathrm{NFI}=0.92 ; \mathrm{RMSEA}=0.070$; Hoelter(0.05) $=204)$, the reverse relationship between organic food involvement and organic food identity $(\beta=0.19, p<0.01)$ was not an improvement to the relationship $(\beta=0.54, p<0.01)$ proposed in the organic food identity model (Table 4).

Competing model $4\left(\chi^{2}=799.36\right.$, d.f. $=145, p<0.01 ; \mathrm{CFI}=0.94 ; \mathrm{NFI}=0.93 ; \mathrm{RMSEA}=0.096$; Hoelter $(0.05)=107)$ was identical to the proposed baseline model but without the control variables. 
This competing model suggested a strong relationship between organic food identity and intentional organic food behavior $(\beta=0.94, p<0.01)$ indicating that a positive bivariate relationship between organic food identity and intentional organic food behavior does exist. However, since organic food identity was not related to intentional organic food behavior in the baseline model (i.e., with the control variables), it also emphasizes that the proposed control variables should indeed be taken into account when seeking a more nuanced understanding of how consumers' organic food identity may transmit into intentional organic food behavior. To conclude, we did not find compelling evidence suggesting that any of the four competing models were superior to the proposed organic food identity model.

\section{Discussion}

The results indicate that consumers' organic food identity is positively driven by health consciousness (an egoistic motive) and negatively driven by social consciousness (a mixture of egoistic and altruistic motives), whereas environmental consciousness (an altruistic motive) was unrelated to organic food identity. Hence, our results suggest the dominance of egoistic motives over altruistic motives in forming consumers' organic food identity. While past research has extensively investigated egoistic vs. altruistic drivers as motivational factors for consumers' green attitude and behavior, the results do not yield a clear picture on whether egoistic or altruistic motives are dominant. Stern et al. (1993) found that motives for consumers' willingness to engage in pro-environmental behavior are based on a combination of egoistic, social-altruistic, and biocentric factors, whereas only awareness of consequences for one-self (egoism) predicts intentions to pay taxes for environmental protection. In contrast, results obtained by Clark et al. (2003) suggest that pro-environmental behavior is most highly motivated by biocentrism, followed by altruism, then egoism, whereas the study by Mondelaers et al. (2009) indicates that individuals attach higher importance to health (egoistic motive) than to sustainability (altruistic motive) when 
making organic food choices. Hartmann and Apaolaza-Ibáñez (2012) concluded that environmental (altruistic) motives influenced consumers' attitude toward green energy brands, whereas selfexpressive (egoistic) motives did not.

Perhaps surprisingly, we found that health consciousness had a higher positive influence on organic food identity with higher levels of all the four investigated personal values. However, the finding that consumers who strongly adhere to openness to change and self-transcendence are more likely to transmit their health consciousness into organic food identity is consistent with previous research suggesting that these value types are positively related to pro-environmental and 'green' behavior (De Pelsmacker et al., 2016). Consumers who believe that conservation is very important may be more likely to seek to comply with prevalent behavioral (green) patterns in the society (Ramayaha et al., 2010), whereas consumers who are adhering to self-enhancement may assign a higher weight to health consciousness as a driver of organic food identity because these consumers are mainly motivated by egoistic motives (e.g., Leonidou et al., 2010). Our finding that selfenhancement negatively moderates the relationship between social consciousness and organic food behavior is therefore also explainable because both social consciousness and organic food identity can be thought of as a mixture of egoistic/altruistic motives and viewpoints.

Organic food identity was not related to intentional organic food behavior in the baseline model. However, and consistent with the proposed organic food identity model, this result was modified in several ways when consumers' personal values were taken into account: (a) Organic food identity had a positive influence on intentional organic food behavior with low levels of openness to change and self-transcendence, respectively. (b) When openness to change was on a low level, health consciousness had a positive effect on intentional organic food behavior, through organic food identity, whereas social consciousness had a negative effect on intentional organic food behavior through food identity. (c) When self-transcendence was on a low level, health consciousness had a positive effect on intentional organic food behavior, through organic food 
identity. Hence, we found evidence that personal values significantly moderate the potential mediating effect of organic food identity in the relationship between motives and intentional organic food behavior.

Several of the control variables had significant effects. For instance, we found that organic food involvement was positively related to both organic food identity and intentional organic food behavior and that females were more likely to develop a positive organic food identity than males. Also, age negatively influenced intentional organic food behavior. These effects are consistent with previous research, which has indicated that involvement in health and sustainability is a key trigger for increasing healthy and sustainable eating (Van Loo et al., 2017) and that females (Ureña et al., 2008) and younger people (Grebitus et al., 2015) are more likely to show a positive attitude towards organic food behavior. The significant influence of social norm on intentional organic food behavior indicates that consumers' purchase of organic food is also affected by which food types are preferred in consumers' social surroundings. Although consumers are willing to pay premiums for organic food products (Hasselbach and Roosen, 2015; D’Amico et al., 2016), we found that the higher price of organic food products may still act as a behavioral barrier for purchasing organic food products. This result is in line with previous studies (e.g., Paul and Rana 2012). However, the results also indicated that price does not significantly reduce consumers' willingness to develop an organic food identity.

\section{Policy implications}

Confidence and trust play significant roles in organic food policy because they substantially influence how consumers filter information. These are especially important for organic foods since they are credence goods (Darby and Karni, 1973). Food producers normally know whether or not their products adhere to organic standards, while consumers are not usually capable of verifying this 
(Müller and Gaus, 2015). Therefore, when dealing with consumer values, the level of consumer trust in the different sources of information must also be considered (Grebitus et al., 2015).

Evidence suggests that consumers have more trust in information from authorities that promote individuals' wellbeing and healthiness (Montserrat et al., 2008) such as government institutions.

Toward this aim, the results indicate that food authorities, food producers and retailers have the opportunity of addressing and segmenting organic food consumers based on their motivations and values.

First, they have opportunities for utilizing the positive influence of health consciousness on organic food identity. Food authorities, and others, may seek to promote consumers' health consciousness by stressing that 'you are what you eat' and by emphasizing that organic food may make consumers feel good about their healthiness. Establishing this link may work especially well for consumers with higher levels of one or more of the four investigated personal values. The conducted segmentation analysis (see Appendix B) suggests that promoting consumers' health consciousness may in particular be relevant for segment 2 as these respondents show high levels of personal values but only low or moderate levels of motivational variables, organic food identity, intentional organic food behavior, organic food involvement, and social norms. Second, the promotion of health consciousness may also result in an improvement of intentional organic food behavior for consumers with low levels of openness to change (i.e., segments 1 and 3) and selftranscendence (i.e., segments 1 and 2), respectively. Third, food authorities also have the opportunity of dealing with the negative relationship between social consciousness and organic food behavior. When promoting a more positive organic food identity among consumers it should be avoided placing them as dependent and social individuals as this would relate to the social consciousness motive. This is even more important when addressing consumers with low values of conservation (i.e., segment 3) and openness to change (i.e., segments 1 and 3), respectively. 
Fourth, it was also found that social norms were positively related to intentional organic food behavior. Social learning theory (Bandura, 1977) posits that social norms, which include shared perceptions of reasonable food behavior, can be altered over time. This implies that organic food campaigns should not only be conducted with regards to the end users as the target group but should also take into account relevant others (e.g. relatives and friends) potentially influencing food consumers. In accomplishing this, food authorities may wish to focus especially on improving the relatively low levels of perceived social norms in segments 1 and 2. Fifth, organic food campaigns may aim at improving organic food involvement in order to positively influence both organic food identity and intentional organic food behavior. While these effects may occur for all consumers, low levels of organic food involvement are especially found in segments 1 and 2. Previous research has suggested a variety of means in accomplishing this; including labeling, informational and educational activities, among others (see Van Loo et al., 2017 for an overview). However, influencing levels of involvement and identity is not easily accomplished and may require a longterm and ambitious effort (e.g., Aertsens et al., 2009; Arnocky et al., 2007). Acknowledging this, organic and sustainable food policies often consist of a package of instruments, which may also include more behavioral-oriented initiatives such as nudging consumers toward more organic choices, exposing school children to various sensory and taste experiences, and improving the affordability of organic food products, among others (Reisch et al., 2013).

\section{Study limitations}

There are four primary limitations of our research. First, while this study focused on three consumer motivations (i.e., environmental, health, and social consciousness), additional consumer motivations (e.g., animal welfare, lack of confidence in conventional foods, nostalgia, among others) may further detail the results. Future research may wish to take such additional motivations into account. 
Second, this study concentrated on analyzing the consumer population of one society/culture. Although organic foods are present in most societies, this could mean that the results may suffer from a lack of generalizability when other countries are considered. Indeed, organic production guidelines and the quality of organic foods are variable across countries (Organic Standards, 2017), which could influence trust in certifying authorities and the extent to which environmental principles and sustainability drive food choice. Cultural characteristics such as e.g., the degree of consumer uncertainty avoidance, among others, could also be important. According to Hofstede (2001), uncertainty avoidance reflects a society's tolerance for uncertainty and ambiguity, where ambiguity can be seen as "the subjective experience of missing information relevant for a prediction" (Frisch and Baron, 1988, p. 152). Since organic foods represent something 'new' as compared with conventional foods, consumers with low tolerance for uncertainty/ambiguity may be less inclined to develop a positive organic food identity and to engage in organic food behavior. Future studies could examine these issues by extending this research to other cultures and/or by manipulating uncertainty avoidance (or other cultural characteristics) in an experimental setting.

Third, future research is also called upon to take into account additional market and consumer characteristics. For example, supply factors, like organic food availability and distance to market (Paul and Rana, 2012) and consumers' perceptions and understanding of the various attributes of organic food products (McFadden and Huffman, 2017) may affect organic food behavior. Also, market characteristics may be regarded differently depending upon the level of personal values. For instance, consumers with high openness to change may be more likely to be open to food trends and fads in the marketplace.

Fourth, we approached a panel of Danish consumers with online surveys about intentions. Consumers may behave differently when engaged in market activities in a food-related, non- 
hypothetical setting. On a similar note, we used perceptive measures from our survey, which could have generated biased responses. 


\section{Appendix A}

Items used to measure the constructs in the study

Baseline model variables

Environmental consciousness ${ }^{f}$

When/if you purchase/ would purchase organic foods,

how important is it to you that this helps to...

$\mathrm{X} 1$. Reduce the amount of chemicals that run-off into lakes and watercourses ${ }^{\mathrm{b}}$

$\mathrm{X} 2$. Reduce the amount of artificial fertilisers in agriculture ${ }^{\mathrm{b}}$

$\mathrm{X} 3$. Reduce the use of herbicides and pesticides in agriculture ${ }^{\mathrm{b}}$

$\mathrm{X} 4$. Reduce the pollution of the soil ${ }^{\mathrm{b}}$

X5. By purchasing organic foods, I help/would help to improve ${ }^{c}$ the general state of the environment

Health consciousness ${ }^{g}$

X6. I regard myself as a health consciousness consumer ${ }^{\mathrm{C}}$

X7. I seek to choose food products that are good for my health

I prefer food products without additives ${ }^{c} \#$

Compared with other people of my age I have a good health ${ }^{\mathrm{c}} \#$

$\mathrm{X} 8$. I believe that I am what $\mathrm{I}_{\text {eat }} \mathrm{c}^{\mathrm{c}}$

Social consciousness ${ }^{f}$

When/if you purchase/ would purchase organic foods,

how important is it to you that this helps to...

X9. Improve my own or my family's health ${ }^{\text {b }}$

X10. Give myself a good conscience ${ }^{b}$

$\mathrm{X} 11$. Reduce the risk for illness in my family ${ }^{\mathrm{b}}$

X12. Give my children better food ${ }^{\mathrm{b}}$

$\mathrm{X} 13$. Avoid risks that may be associated with eating non-organic foods ${ }^{\mathrm{b}}$

Organic food identity ${ }^{h}$

X14. I think of myself as an organic food consumer ${ }^{c}$

$\mathrm{X} 15$. I think of myself as a 'green' consumer'

X16. I would describe myself as an organic conscious consumer ${ }^{c}$

Intentional organic food behavior ${ }^{i}$

$\mathrm{X} 17$. I intend to purchase organic food/more organic food within the near future

X18. I want to purchase organic food/more organic food within the near future ${ }^{\mathrm{d}}$

$\mathrm{X} 19$. How likely is it that you will purchase organic produce within the next fortnight $\mathrm{e}^{\mathrm{e}}$
Percentages in scale categories ${ }^{\mathrm{a}}$

1 or 23,4 or $5 \quad 6$ or 7

$\begin{array}{ccc}12.3 & 36.8 & 50.9 \\ 11.3 & 35.8 & 53.0 \\ 13.8 & 35.5 & 50.7 \\ 10.7 & 40.3 & 49.0 \\ 10.1 & 40.7 & 49.2\end{array}$

$3.9 \quad 51.5 \quad 44.6$

$\begin{array}{lll}7.4 & 56.7 \quad 35.9\end{array}$

$8.9 \quad 46.5 \quad 44.6$

$23.3 \quad 46.1 \quad 30.6$

$\begin{array}{lll}7.2 & 48.0 \quad 44.7\end{array}$

$13.7 \quad 41.7 \quad 44.6$

$\begin{array}{lll}17.5 & 47.3 \quad 35.3\end{array}$

$32.4 \quad 50.0 \quad 17.6$

$28.2 \quad 49.4 \quad 22.4$

$27.4 \quad 46.9 \quad 25.7$

$\begin{array}{lll}32.6 & 40.7 \quad 26.7\end{array}$

$14.0 \quad 59.5 \quad 26.5$

$18.8 \quad 57.9 \quad 23.4$

$\begin{array}{lll}24.4 & 43.3 & 32.3\end{array}$

$\begin{array}{lll}27.3 & 42.7 & 30.0\end{array}$

$23.0 \quad 37.6 \quad 39.4$

\section{$\underline{\text { Moderating variables }}$}

Conservation $^{\mathrm{j}}$

X20. Correctness ${ }^{\mathrm{c}}$

X21. Respect authorities ${ }^{\mathrm{c}}$

Humble and modest ${ }^{\mathrm{c}}$ \#

X22. Tradition $^{\mathrm{c}}$

X23. Secure surroundings ${ }^{c}$

Strong state ${ }^{\mathrm{c}}$ \#

Openness to change $\mathrm{e}^{\mathrm{j}}$

$\mathrm{X} 24$. Varied life $\mathrm{c}^{\mathrm{C}}$ 
Self-enhancement ${ }^{\mathrm{j}}$

X28. Social successfulness ${ }^{\mathrm{C}}$

X29. Capable

X30. Rich ${ }^{\mathrm{c}}$

X31. Respect from others ${ }^{c}$

No waste of time ${ }^{\mathrm{c}}$ \#

Self-transcendence $e^{\mathrm{j}}$

Equal opportunities in $\operatorname{life}^{c} \#$

Care for nature ${ }^{\mathrm{c}} \#$

$\mathrm{X} 33$. Loyal to friends ${ }^{\mathrm{c}}$

$4.1 \quad 32.8 \quad 63.1$

\section{Control variables}

Organic food involvement ${ }^{k}$

$\mathrm{X} 34$. Organic food matters a lot to $\mathrm{me}^{\mathrm{c}}$

$\mathrm{X} 35$. It is unimportant whether food items are organic or conventional ${ }^{\mathrm{c}}$

Social norm ${ }^{l}$

$\mathrm{X} 37$. People in my family think it is a good idea to purchase organic food $\mathrm{d}^{\mathrm{c}}$

$\mathrm{X} 38$. Most of my friends and acquaintances think that it is a good idea to purchase organic food ${ }^{\mathrm{c}}$

X39. Most of the people that are important to me have a positive attitude towards organic food ${ }^{\mathrm{c}}$

Perceived organic food price ${ }^{m}$

Organic food...

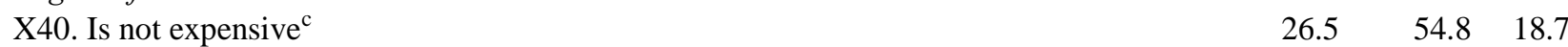

$\mathrm{X} 41$. Is cheap ${ }^{\mathrm{c}}$

$\mathrm{X} 42$. Is good value for money ${ }^{\mathrm{c}}$

\# Item deleted due to low $(<0.50)$ item-total correlation. Sample $n=1,176$.

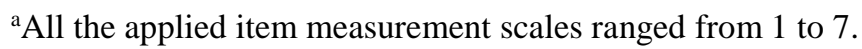

${ }^{\mathrm{b}}$ Scale ranging from 1 (=not at all important) to 7 (=extremely important).

${ }^{\mathrm{c}}$ Scale ranging from 1 (=strongly disagree) to 7 (=strongly agree).

${ }^{\mathrm{d}}$ Scale ranging from 1 (=definitely not) to 7 (=definitely).

${ }^{\text {e}}$ Scale ranging from 1 (=not at all likely) to 7 (=very likely).

fEnvironmental and social consciousness: Items were adapted from Magnusson et al. 2003. X12: If 'no children' was stated (11.4\% of the cases), the respondent's answer was replaced with the mean of the remaining respondents.

'Health consciousness: Items were derived from Squires et al. (2001).

${ }^{\mathrm{h}}$ Organic food identity: Items were derived from Sparks and Shepherd (1992).

intentional organic food behavior: Items were derived from Michaelidou and Hassan (2008).

jItems adapted from the European Social Survey's 21-item value instrument (Davidov et al., 2008).

${ }^{k}$ Items derived from Mittal (1989).

${ }^{1}$ Items derived from Hansen (2008).

mItems adapted from Steptoe et al. (1995). 


\section{Appendix B}

Segmentation analysis

\begin{tabular}{|c|c|c|c|c|c|c|c|c|c|}
\hline & \multirow[b]{2}{*}{$\begin{array}{l}\text { Mean } \\
\text { square }\end{array}$} & \multirow[b]{2}{*}{ df } & \multirow[b]{2}{*}{$F$-value } & \multirow[b]{2}{*}{ Sig. } & \multicolumn{4}{|c|}{ Segment (mean) $)^{\mathrm{a}}$} & \multirow[b]{2}{*}{ Mean comparison ${ }^{b}$} \\
\hline & & & & & $\begin{array}{c}\mathrm{S} 1 \\
(21.2 \%)\end{array}$ & $\begin{array}{c}\mathrm{S} 2 \\
(23.0 \%) \\
\end{array}$ & $\begin{array}{c}\text { S3 } \\
(28.1 \%) \\
\end{array}$ & $\begin{array}{c}\mathrm{S} 4 \\
(27.7 \%) \\
\end{array}$ & \\
\hline \multicolumn{10}{|l|}{ Baseline model variables } \\
\hline Environmental consciousness & 79.32 & 3 & 70.67 & $<0.01$ & 3.28 & 4.77 & 3.26 & 4.37 & $\mathrm{~S} 2>\mathrm{S} 1, \mathrm{~S} 3, \mathrm{~S} 4 ; \mathrm{S} 4>\mathrm{S} 1, \mathrm{~S} 3$ \\
\hline Health consciousness & 89.14 & 3 & 128.36 & $<0.01$ & 4.40 & 4.60 & 5.13 & 6.18 & $\mathrm{~S} 4>\mathrm{S} 1-\mathrm{S} 3 ; \mathrm{S} 3>\mathrm{S} 1, \mathrm{~S} 2$ \\
\hline Social consciousness & 372.24 & 3 & 541.91 & $<0.01$ & 2.11 & 3.79 & 4.78 & 6.07 & $\mathrm{~S} 4>\mathrm{S} 1-\mathrm{S} 3 ; \mathrm{S} 3>\mathrm{S} 1, \mathrm{~S} 2 ; \mathrm{S} 2>\mathrm{S} 1$ \\
\hline Intentional organic food behavior & 589.43 & 3 & 863.97 & $<0.01$ & 1.66 & 3.48 & 5.15 & 6.51 & $\mathrm{~S} 4>\mathrm{S} 1-\mathrm{S} 3 ; \mathrm{S} 3>\mathrm{S} 1, \mathrm{~S} 2 ; \mathrm{S} 2>\mathrm{S} 1$ \\
\hline \multicolumn{10}{|l|}{ Moderating variables } \\
\hline Conservation & 15.12 & 3 & 10.27 & $<0.01$ & 4.32 & 4.85 & 4.16 & 4.74 & $\mathrm{~S} 2, \mathrm{~S} 4>\mathrm{S} 1, \mathrm{~S} 3$ \\
\hline Openness to change & 22.31 & 3 & 19.24 & $<0.01$ & 4.28 & 4.67 & 4.26 & 5.08 & $\mathrm{~S} 4, \mathrm{~S} 2>\mathrm{S} 1, \mathrm{~S} 3$ \\
\hline Self-enhancement & 79.32 & 3 & 70.67 & $<0.01$ & 3.28 & 4.77 & 3.26 & 4.37 & $\mathrm{~S} 2>\mathrm{S} 1, \mathrm{~S} 3, \mathrm{~S} 4 ; \mathrm{S} 4>\mathrm{S} 1, \mathrm{~S} 3$ \\
\hline Self-transcendence & 42.92 & 3 & 50.57 & $<0.01$ & 5.13 & 5.22 & 5.38 & 6.31 & $\mathrm{~S} 4>\mathrm{S} 1-\mathrm{S} 3 ; \mathrm{S} 3>\mathrm{S} 1$ \\
\hline \multicolumn{10}{|l|}{ Control variables } \\
\hline Social norm & 217.68 & 3 & 297.73 & $<0.01$ & 2.77 & 3.91 & 4.78 & 5.76 & $\mathrm{~S} 4>\mathrm{S} 1-\mathrm{S} 3 ; \mathrm{S} 3>\mathrm{S} 1, \mathrm{~S} 2 ; \mathrm{S} 2>\mathrm{S} 1$ \\
\hline Perceived price & 278.56 & 3 & 357.95 & $<0.01$ & 6.04 & 4.93 & 3.86 & 2.69 & $\mathrm{~S} 1>\mathrm{S} 2-\mathrm{S} 4 ; \mathrm{S} 2>\mathrm{S} 3, \mathrm{~S} 4 ; \mathrm{S} 3>\mathrm{S} 4$ \\
\hline Gender $^{\mathrm{c}}$ & - & - & - & - & 37.3 & 36.7 & 50.6 & 51.9 & $\chi^{2}=11.39, p=0.01$ \\
\hline Age (years) & 66.78 & 3 & 0.44 & 0.73 & 57.4 & 56.4 & 57.6 & 58.0 & N.a. \\
\hline Education & 12.94 & 3 & 10.82 & $<0.01$ & 3.35 & 3.34 & 3.51 & 3.99 & $\mathrm{~S} 4>\mathrm{S} 1-\mathrm{S} 3$ \\
\hline Income & 1.55 & 3 & 1.29 & 0.28 & 0.92 & 3.10 & 2.84 & 3.02 & N.a. \\
\hline
\end{tabular}

A two-step cluster process was utilized. First, hierarchical clustering was used to identify the numbers of clusters implied by the data. Then, $k$-means clustering was used to fine-tune the results from the hierarchical procedure. The between-groups linkage method of clustering using the squared Euclidean distance was applied in the initial hierarchical approach to develop the number of clusters. A review of the percentage change on the agglomeration coefficient suggested a four-cluster/segment solution. In the second-stage, four clusters were therefore specified. Sample $n=1,176$.

The latent baseline model variables, moderating variables, and control variables were averaged before entering the cluster analysis. The segment means/proportions of the variables gender, age, education, and income were not included in the cluster analysis but were calculated ex post. Education and income were measured as displayed in Table 1.

${ }^{a}$ Percentages in parantheses display the proportion of respondents in the segments. ${ }^{b}$ Mean comparisons were conducted by Fisher's least significant difference (LSD), $5 \%$ significance level. ${ }^{\circ}$ Gender displays the percentage of female respondents in the segments. N.a.: Not applicable ( $F$-value was not significant). 


\section{References}

Aertsens, J., Verbeke, W., Mondelaers, K., Van Huylenbroeck, G., 2009. Personal determinants of organic food consumption: a review. Brit. Food J. 111, 1140-1167.

Ajzen, I., Fishbein M., 1973. Attitudinal and normative variables as predictors of specific behaviors. J. Pers. Soc. Psychol. 27, 41-57.

Arnocky, S., Stroink, M., DeCicco, T., 2007. Self-construal predicts environmental concern, cooperation, and conservation. J. Environ. Psychol. 27, 255-264.

Atkinson, L., 2012. Buying in to social change: how private consumption choices engender concern for the collective. Ann. Am. Acad. Political Soc. Sci. 644, 191-206.

Bagozzi, R.P., Yi Y., 1988. On the evaluation of structural equation models. J. Acad. Mark. Sci. 16, 74-94.

Bandura, A., 1977. Social learning theory, Englewood Cliffs, N.J.: Prentice-Hall.

Becker, M.H., Maiman, L.A., Kirscht, J.P., Haefner, D.P., Drachman, R.H., 1977. The health belief model and prediction of dietary compliance: A field experiment. J. Health Soc. Behav. $18,348-366$.

Belk, R.W., 1988. Possessions and the extended self. J. Consum Res. 15, 139-168.

Buckley, M.R., Cote, J.A., Comstock, S.M., 1990. Measurement errors in behavioral sciences: The case of personality/attitude research. Educ. Psychol. Meas. 50, 447-474.

Claeys, C., Swinnen, P., Vanden Abeele, P., 1995. Consumer's means-end chains for "think" and "feel" products. Int. J. Res. Mark. 12, 193-208.

Clark, C.F., Kotchen, M.J., Moore, M.R., 2003. Internal and external influences on proenvironmental behavior: Participation in a green electricity program. J. Environ. Psychol. 23, 237-246.

Darby, M. R., Karni, E., 1973. Free competition and the optimal amount of fraud. J. Law Econ. 
$16,67-86$.

D'Amico, M., Di Vita, G., Monaco, L., 2016. Exploring environmental consciousness and consumer preferences for organic wines without sulfites. J. Clean. Prod. 120, 64-71.

Davidov, E., Schmidt, P., Schwartz, S.H., 2008. Bringing values back in: the adequacy of the European social survey to measure values in 20 countries. Public Opin. Q. 72, 420-445.

De Marchi, E., Caputo, V., Nayga, R.M. Jr., Banterle, A., 2016. Time preferences and food choices: Evidence from a choice experiment. Food Policy 62, 99-109.

De Maya, S.R., López-López, I., Munuera, J.L., 2011. Organic food consumption in Europe: International segmentation based on value system differences. Ecol. Econ. 70, 1767-1775.

De Pelsmacker, P., Moons, I., Bavarossa C., 2016. A self-identity driven model of electric car adoption and the moderating role of personal values, Paper presented at the15th International Conference Marketing Trends 2016 Venice. ed. /Jean-Claude Andreani; Umberto Collesei. Paris-Venice: Marketing Trends Association.

DST (Danmarks Statistik) (2017), Statbank Denmark: http://www.dst.dk/da/Statistik/statistikbanken\# (accessed 17 March 2017).

Fisher, E., Arnold, S.J., 1994. Sex, gender identity, gender role attitude, and consumer behavior. Psychol. Mark. 11, 163-182.

Fornell, C., Larcker, D.F., 1981. Evaluating structural equation models with unobservable variables and measurement error. J. Mark. Res. 18, 39-50.

Frambach, R.T., Prabhu, J., Verhallen, T.M.M., 2003. The influence of business strategy on new product activity: The role of market orientation. Int. J. Res. Mark. 20, 377-397.

Frisch, D., Baron, J. 1988. Ambiguity and rationality. J. Behav. Decis. Mak. 1, 149-157.

Grebitus, C., Steiner, B., Veeman, M., 2015. The roles of human values and generalized trust on stated preferences when food is labeled with environmental footprints: Insights from Germany. Food Policy 52, 84-91. 
Greene, W.H., 2000. Econometric analysis. Upper Saddle River, NJ: Prentice Hall.

Grunert, S. C., Juhl, H.J., 1995. Values, environmental attitudes, and buying of organic foods. J. Econ. Psychol. 16, 39-62.

Hansen, T., 2008. Consumer values, the theory of planned behavior and online grocery shopping. Int. J. Consum. Stud. 32, 128-137.

Hansen, T., Risborg, M.S., Steen, C.D., 2012. Understanding consumer purchase of free-of cosmetics: A value-driven TRA approach. J. Consum. Behav. 11, 477-486.

Hansen, T., Thomsen, T.U., 2013. I know what I know, but I will probably fail anyway: How learned helplessness moderates the knowledge calibration-dietary choice quality relationship. Psychol. Mark. 30, 1008-1028.

Hansen, T., Thomsen, T.U., 2017. Weight loss for the mind: Consumers' construction of food related health values and their impact on food health behaviour. Proceedings of the $16^{\text {th }}$ International Conference Marketing Trends Madrid. ed. /Jean Claude Andreani; Umberto Collesei. Paris-Venice: Marketing Trends Association 2017.

Hartmann, P., Apaolaza-Ibáñez, V., 2012. Consumer attitude and purchase intention toward green energy brands: The roles of psychological benefits and environmental concern. J. Bus. Res. 65, 1254-1263.

Hasselbach, J.L., Roosen, J., 2015. Motivations behind preferences for local or organic food. J. Int. Consum. Mark. 27, 295-306.

Hoelter, J.W. 1983. The analysis of covariance structures: goodness-of-fit indices. Sociol. Methods Res. 11, 325-344.

Hofstede, G., 2001. Culture's consequences. London: Sage Publications. Holt, D., Smith, T.M.F., 1979. Post stratification. J R Stat Soc. Series A (General) 142, 33-46. Iyer, P., Davari, A., Paswan, A., 2016. Green products: Altruism, economics, price fairness and purchase intention. Soc. Bus. 6, 39-64. 
Jayawardhena, C., 2004. Measurement of service quality in internet banking: The development of an instrument. J. Mark. Manage. 20, 185-207.

Johnston, C.S., 1995. The Rokeach value survey: Underlying structure and multidimensional scaling. J. Psychol. 129, 583-597.

Kahle, L.R., Kennedy, P., 1989. Using the list of values (LOV) to understand consumers. J. Consum. Mark. 6, 5-12.

Kareklas, I., Carlson, J., Muehling, D., 2014. I eat organic for my benefit and yours: Egoistic and altruistic considerations for purchasing organic food and their implications for advertising strategists. J. Advert. 43, 18-32.

Kilbourne, W.E., Beckmann, S.C., 1998. Review and critical assessment of research on marketing and the environment. J. Mark. Manage. 14, 513-532.

Kilbourne, W., Grünhagen, M., Foley, J., 2005. A cross-cultural examination of the relationship between materialism and individual values. J. Econ. Psychol. 26, 624-641.

Kline, R.B. 2016. Principles and Practice of Structural Equation Modeling, 4th ed. New York: Guilford Press.

Kriwy, P., Mecking, R-A., 2012. Health and environmental consciousness, costs of behaviour and the purchase of organic food. Int. J. Consum. Stud. 36, 30-37.

Krupka, E., Weber, R.A., 2009. The focusing and informational effects of norms on pro-social behavior. J. Econ. Psychol. 30, 307-320.

Lance, P.M., Hattori, A., 2016. Sampling and Evaluation. Chapel Hill, North Carolina: MEASURE Evaluation, University of North Carolina.

Lee, H-J., 2016. Individual and situational determinants of U.S. consumers' buying behavior of organic foods. J. Int. Food Agribus. Mark. 28, 117-131.

Leonidou, L.C., Leonidou, C.N., Kvasova, O., 2010. Antecedents and outcomes of consumer environmentally friendly attitudes and behaviour. J. Mark. Manage. 26, 1319-1344. 
MacCallum, R.C. and J.T. Austin. 2000. Applications of structural equation modeling in Psychological Research. Annu. Rev. Psychol. 51, 201-226.

Magnusson, M.K., Arvola, A., Koivisto-Hursti, U.K., Åberg, L., Sjöden, P.O., 2003. Choice of organic foods is related to perceived consequences for human health and environmentally friendly behavior. Appetite 40, 109-117.

Marchand J., Khallaayoune, Z., 2010. 'LOV' and the big screen: A value-system segmentation of movie goers. J. Target Meas. Anal. Market. 18, 177-188.

McFadden, J.R., Huffman, W.E., 2017. Willingness-to-pay for natural, organic, and conventional foods: The effects of information and meaningful labels. Food Policy 68, 214-232.

Michaelidou, N., Hassan, L.M., 2008. The role of health consciousness, food safety concern and ethical identity on attitude and intensions towards organic food. Int. J. Consum. Stud. 32, 163-170.

Mittal, B., 1989. Measuring purchase-decision involvement. Psychol. Mark. 6, 147-162.

Mondelaers, K., Verbeke, W., Van Huylenbroeck, G., 2009. Importance of health and environment as quality traits in the buying decision of organic products. Brit. Food J. 111, 1120-1139.

Montserrat, C-F., Gill, J.M., Traill, W.B., 2008. Consumer acceptance, valuation of and attitudes towards genetically modified food: Review and implications for food policy. Food Policy 33, 99-111.

Müller, C.E., Gaus, H., 2015. Consumer response to negative media information about certified organic food products. J. Consum. Policy 38, 387-409.

Netemeyer, R.G., Boles, J.S., McKee, D.O., McMurrian, R.C., 1997. An investigation into the antecedents of organizational citizenship behaviors in a personal selling context. J. Mark. 61, 85-98.

O’Fallon, M.J., Butterfield, K.D., 2012. The influence of unethical peer behavior on observers' unethical behavior: A social cognitive perspective. J. Bus. Ethics 109, 117-131. 
Organic Standards 2017: International certification norms for organic food production.

https://www.organic-standards.info/ (Accessed July 2017).

Padel, S., Röcklinsberg, H., Schmid O., 2009. The implementation of organic principles and values in the European regulation for organic food. Food Policy 34, 245-251.

Paul, J., Rana, J., 2012. Consumer behavior and purchase intention for organic food. J. Consum. Mark. 29, 412-422.

Ramayaha, T., Jason, W., Osman, M., 2010. Green products purchase intention: Some insights from a developing country. Res. Cons. Recycl. 54, 1419-1427.

Reisch, L.A., Eberle, U., Lorek, S., 2013. Sustainable food consumption: an overview of contemporary issues and policies. Sustainability: Sci. Pract. Policy 9, 7-25.

Rise, J., Sheeran, P., Hukkelberg, S., 2010. The role of self-identity in the theory of planned behavior: A meta-analysis. J. Appl. Soc. Psychol. 40, 1085-1105.

Rokeach, M., 1973. The nature of human values. New York: The Free Press.

Schwartz, S.H., 1994. Are there universal aspects in the structure and contents of human values? J. Soc. Issues 50, 19-45.

Schwartz, S.H., Sagiv L., 1995. Identifying culture-specifics in the content and structure of Values. J. Cross. Cult. Psychol. 26, 92-116.

Sparks, P., Shepherd, R., 1992. Self-identity and the theory of planned behavior. Assesing the role of identification with "green consumerism". Soc. Psychol. Q. 55, 388-399.

Squires, L., Juric, B., Cornwell, T.B., 2001. Level of market development and intensity of organic food consumption: cross-cultural study of Danish and New Zealand consumers. J. Consum. Mark. 18, 392-409.

Steptoe, A., Pollard, T.M., Wardle, J., 1995. Development of a measure of the motives underlying the selection of food: The food choice questionnaire. Appetite 25, 267-284.

Stern, P.C., Dietz, T., Kalof, L., 1993. Value orientations, gender and environmental concern. 
Environ. Behav. 25, 322-348.

Stets, J.E., Burke, P.J., 2003. A sociological approach to self and identity. In: M.R. Leary and J.P. Tangney (Eds.), Handbook of self and identity, The Guilford Press, New York, 128-152.

Tarkiainen, A., Sundqvist, S., 2009. Product Involvement in organic food consumption: Does ideology meet practice? Psychol. Mark. 26, 844-863.

Thompson, C., Troester, M., 2002. Consumer value systems in the age of postmodern fragmentation: The case of the natural health microculture. J. Consum. Res.28, 550-571.

Ureña, F., Bernabéu, R., Olmeda, M., 2008. Women, men and organic food: differences in their attitudes and willingness to pay. A Spanish case study. Int J Consum Stud. 32, 18-26.

Van Loo, E.J.,, Hoefkens, C., Verbeke, W., 2017. Healthy, sustainable and plant-based eating: Perceived (mis)match and involvement-based consumer segments as targets for future policy. Food Policy 69, 46-57.

Warshaw, P.R., 1980. Predicting purchase and other behaviors from general and contextually specific intentions. J. Mark. Res. 17, 26-33.

Webster Jr, F.E., 1975. Determining the characteristics of the socially conscious consumer. J. Consum. Res. 2, 188-196.

Ye, J., Marinova, D., Singh, J., 2007. Strategic change implementation and performance loss in the front lines. J. Mark. 71, 156-171. 